\title{
Bulla-like Malherbe's Calcyfying Epithelioma Induced by Deltoid Muscle Rupture
}

\author{
Betul Tas ${ }^{1 *}$, Seyda Andac ${ }^{2}$, Idris Ersin ${ }^{3}$, Aysel Caglar ${ }^{4}$ \\ ${ }^{I}$ Health Sciences University, Istanbul Bagcilar Research and Training Hospital, Department of Dermato \\ venereology, Istanbul/Turkey \\ ${ }^{2}$ Health Sciences University, Istanbul Bagcilar Research and Training Hospital Department of Radio \\ diagnostic, Istanbul/Turkey \\ ${ }^{3}$ Health Sciences University, Istanbul Bagcilar Research and Training Hospital Department of Aesthetic, \\ Plastic and Reconstructive Surgery, Istanbul/Turkey \\ ${ }^{4}$ Health Sciences University, Istanbul Bagcilar Research and Training Hospital, Department of Pathology, \\ Istanbul/Turkey \\ *Corresponding Author: Betul Tas, Health Sciences University, Istanbul Bagcilar Training and \\ Research Hospital, Department of Dermatovenereology, Istanbul/Turkey, Email: betulavc@yahoo.com
}

\begin{abstract}
Pilomatricomas are usually benign and relatively common skin tumors which orginate from primitive cells of the hair matrix. The typical appearance of the tumor is usually soliter, firm, flesh-colored and asymptomatic nodule beneath the skin, and usually affects young individuals. In recent years, except for the typical clinical presentation, some atypical bulla-like lesions have been reported. It has been stated that mechanical irritation, pricking or blunt trauma could be the most likely contributing factors. Herein we report a 28 year-old man with bullous pilomatricoma which developed after a deltoid muscle rupture in the course of a weight-lifting exercise. To the best of our knowledge the lesion is the first example of bulla-like pilomatricoma induced by a muscle rupture.
\end{abstract}

Keywords: Skin diseases; vesiculobullous; Muscle fibers; skeletal; muscle stretching exercise; pilomatricoma

\section{INTRODUCTION}

Pilomatricoma also known as calcifying epithelioma was first described by Malherbe and Chenantais in 1880. It is usually an asymptomatic lesion. The typical presentation of the tumor is soliter, firm, flesh-colored and asymptomatic nodule beneath the skin. In recent years, except for the typical clinical presentation, some different manifestations of the tumor have been reported as bullous, bullalike, anetodermic, atrophodermic and perforating $[1,2]$.

\section{CASE REPORT}

A 28 year-old young man was admitted to our dermatology clinic due to his odd-looking shoulder mass. According to the patient's history, just after a weight-lifting exercise, he felt a sudden and sharp pain in his left shoulder 6 months ago. Due to his ongoing shoulder pain, he was admitted to an orthopedist two weeks after, and was diagnosed with deltoid mucle tear. Then, he was prescribed some pain medications and the patient's complaint was improved in a two weeks period only leaving a bruise-like blemish. Two and half months ago he noticed a slight bulging on the traumatic region and it grew increasingly in size. The patient did not state that he was subjected to any other pricking or blunt trauma. Personal, and family histories were unremarkable. In the dermatological examination, a spindle-shaped, swollen, bright-red colored, $4.5 \times 2.5 \mathrm{~cm}$ in size and semi-translucent lesion was seen on the left deltoid region. At both ends of the long axis of the lesion, there were stria-like atrophic triangles (Figure 1a). With palpation, a deep, firm, non-tender nodule was felt beneath the bulla. Physical examination findings were normal and there was no regional lymphadenopathy. Dermatoscopic examination showed, irregular white opacities located on a blurred and livid-red background which were surrounded by red-colored tortuous small structures (Figure 1b). Routine hematological and biochemical examinations of the patient 
were normal. The superficial soft tissue ultrasonograpy showed $4.6 \times 2.8 \mathrm{~cm}$ diameter, a well-circumscribed, heterogen and hypo-echoic soft tissue mass. When the skin was removed, a hemorrhagic fluid and a white $1 \times 1 \mathrm{~cm}$ calcifying and rough tumor was observed, and lesion was totally excised (Figure 1c). On histopathological examination, the tumor nests composed of eosinophilic shadow cells,

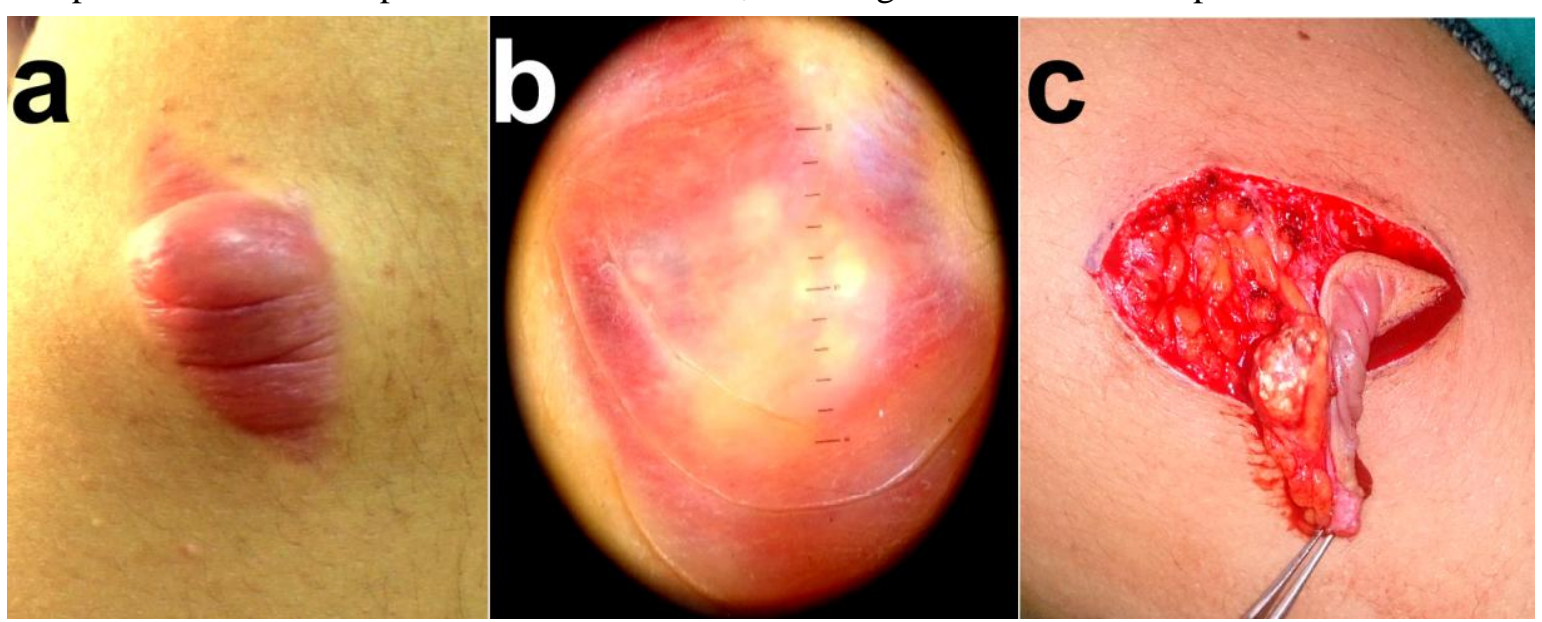

Figure1. A bullous mass on the left deltoid region of the patient (a). Dermatoscopic appearance of the lesion (b). A whitish and rough calcified tumor was seen when the overlying skin was removed (c).

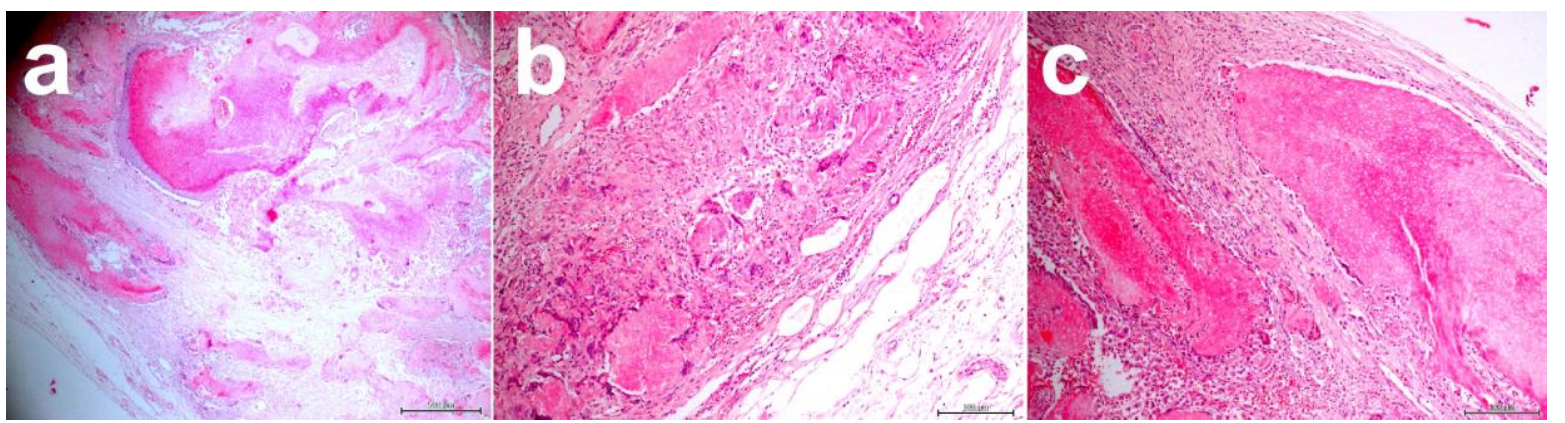

Figure2. The tumor containing epithelial islands of basophilic and shadow cells, multinucleated giant cells, small calcium accumulations in the deep dermis, and dilated small lymphatic vessels, and lymphedema in the superficial dermis (a. HEX40, b. HEX100, c. HEX100).

\section{DISCUSSION}

The bullous pilomatricomas are located in mostly in shoulder and upper extremity and predominantly found in females, and their incidence is between 3\%-6\% [3]. Different clinical manifestations of bullous pilomatricomas have been described as erythematous, bluish or skin-colored, semi-transparent, heavily folded or striae-like, flaccid blisters, overlying a solitary, firm nodule [4]. The skin overlying pilomatricoma can sometimes be atrophic. It is supposed that this atrophic appearance is related to the loss of elastic fibers and dermal edema [3]. Mechanic irritations such as continuous mechanic stimulation, scratching and pinching trauma and continuous pressure play an important role in the development of bullous basophilic cells, multinucleated giant cells and small calcium salt accumulations surrounded by a fibrous capsule in the deep dermis were detected. In the superficial and mid dermis, moderate lymphedema and increased numbers of dilated lymphatics filled with eosinophilic lymph fluid were observed (Figure 2a,b,c). With the clinicopathological findings the patient was diagnosed with bullous pilomatricoma. 
dilation of lymphatic vessels [1,2]. At the end of these processes, the dermis is filled with lymphatic fluid [1]. The common dermatoscopic findings of bullous pilomatricomas are reddish homogenous areas, irregular white structures and hairpin-like atypical vessels [7]. We also obtained similar findings with dermatoscopy. In the histopathology of bullous pilomatricomas, in addition to the classical histopathological findings such as shadow cells, basophilic cells, foreign body cells, calcified focus or even ossification, dilated lymphatic vessels and lymphedema in the superficial dermis are seen $[1,2]$. Sometimes, focal loss or a marked reduction of elastic fibers in the dermis are also seen [3]. Although pilomatricomas can be associated with other genetic disorders such as Curschmann-Steinert myotonic dystrophy and Gardner's syndrome, these associations have not been described in bullous variants $[1,6]$. In differential diagnoses, lymphangioma, bullous morphea, secondary anetoderma and malignant tumors should be considered [6]. Since the lesions do not regress spontaneously and recurrence is rare, treatment of choice is surgical excision $[1,3,6]$

\section{REFERENCES}

[1] Chen SY, Wu F, Qian Y, Zhu L, Tu YT, Huang CZ. Pilomatricoma with bullous appearence:a case report and review of literature. Int $\mathbf{J}$ Dermatol 2011;50(5):615-8. [Pubmed]

[2] Lao LM, Kumakiri M, Kiyohara T, Sakata K, Takeuchi A. Papillary Endhotelial Hyperplasia and dilateded lymphatic vessels in bullous pilomatricoma. Acta Derm Venereol 2005;85(2):160-3. [Pubmed]

[3] de Giorgi V, Alfaioli B, Massi D, Gori A, Sestini S, Papi F, et al. Bullous Pilomatricoma:A particular and Rare Dermal Bullous Disorder. Acta Derm Venereol 2009;89(2):189-90. [Pubmed]

[4] Bhushan P, Hussain SN. Bullous pilomatricoma: A stage in transition to secondary anetoderma? Indian J Dermatol Venereol Leprol 2012;78(4):484-7. [Pubmed]

[5] Inui S, Kanda R, Hata S. Pilomatricoma with a bullous appearance. J Dermatol. 1997;24(1):579. [Pubmed]

[6] Cao HL, Chen JS, Yan JL, Wang JY. Pilomatricoma with a bullous appearance. Indian J Dermatol Venereol Leprol. 2015;81(1):77-8. [Pubmed]

[7] Zaballos P, Llambrich A, Puig S, Malvehy J. Dermoscopic findings of pilomatricomas. Dermatology 2008;217(3):225-30. [Pubmed]

Citation: Betul Tas, Seyda Andac, Idris Ersin, Aysel Caglar. Bulla-like Malherbe's Calcyfying Epithelioma Induced by Deltoid Muscle Rupture. ARC Journal of Dermatology. 2018; 3(1):1-3. doi:dx.doi.org/10. 20431/2456-0022.0301001.

Copyright: (C) 2018 Authors. This is an open-access article distributed under the terms of the Creative Commons Attribution License, which permits unrestricted use, distribution, and reproduction in any medium, provided the original author and source are credited. 